\title{
FERREIRA, Jaqueline e FLEISCHER, Soraya (org.). 2014. Etnografias em serviços de saúde. Rio de Janeiro: Garamond. 360 pp.
}

\author{
TATIANE VIEIRA BARROS
}

O livro publicado em 2014, organizado por Jaqueline Ferreira, professora do Instituto de Saúde Coletiva da UFRJ e por Soraya Fleischer, professora do Departamento de Antropologia da UnB, reúne 12 artigos que apresentam panoramas de pesquisas etnográficas realizadas em serviços de saúde no Brasil e também na França. Este tema, que cada dia mais ganha atenção da antropologia brasileira, traz consigo uma abordagem teórico e metodológico que tem sido aprimorado pelas pesquisas atuais e se evidencia como um campo de investigação deslocando o olhar que as ciências da saúde têm sobre o corpo e adoecimento e os serviços de saúde. Atentando para a construção social e relacional destes que articulam, também, sistemas terapêuticos e saberes não hegemônico.

Com prefácio da antropóloga Cynthia Sarti e apresentação das organizadoras, o livro traz já em seu sumário um primeiro convite. Lá é possível observar a variedade de temas e de nuances das pesquisas etnográficas em serviços de saúde. $\mathrm{O}$ conjunto de artigos apresentados no livro tem como característica comum a análise etnográfica de serviços de saúde resultantes das orientações do SUS (Sistema Único de Saúde). Trazendo questões que vão além daquelas fixadas pelos saberes biomédicos que findam por homogeneizar formas de serviços e de relações e oferecem noção sobre a complexidade de discussões possíveis de serem realizadas.

Adentrando o livro, percebemos como questóes cotidianas do atendimento, do uso de medicamentos, dos cuidados e das trajetórias de pacientes e usuários, bem como as questões éticas dessas pesquisas tem grande potencial para a descrição etnográfica. Os artigos do livro nos permitem acessar universos dos serviços de saúde por olhares ampliados, sobretudo, pois são escritos por pesquisadores com formação em Ciências Sociais, Medicina e Saúde Coletiva, mas que trazem a reflexão antropológica como cerne de suas questões.

Em seu conjunto, o livro proporciona uma visão analítica ampliada diante das questões de saúde e doença, dor e sofrimento, cuidado e disciplinarização dos corpos, mas também permite ver o impacto dessas experiências nas práticas terapêuticas e nas formas como os sujeitos lidam com o adoecimento e agenciam seus lugares e suas práticas frente aos serviços de saúde. Ele deixa evidente a importância das pesquisas etnográficas para o campo da saúde, trazendo à tona tanto as visões sobre os serviços de saúde quanto às imagens que os envolvidos nesses contextos elaboram sobre os "outros". Isto oferece 
potencial para falar como os serviços de saúde são campos para discutir outros aspectos de modo que "trazer à tona tantas visões nos ajuda a entender, mais e mais, como falar de serviços de saúde é falar de política, corpo, gênero, poder, classe social e raça - e também de saúde." (p.19)

Os artigos organizados neste livro nos levam a caminhar pelo terreno das etnografias nos serviços de saúde. Estão presentes etnografias que discutem as questões da Reforma Psiquiátrica Brasileira e as narrativas dos interlocutores, tendo como campo serviços de saúde mental, hospitais psiquiátricos, Centro de Atenção Psicossocial (CAPS). Artigos relacionados à cotidianos e trajetórias de sujeitos no contexto da reforma psiquiátrica brasileira, participantes de uma oficina de criatividade em um hospital psiquiátrico, dilemas na/da Reforma Psiquiátrica, permitem acessar as linguagens da loucura, evidenciando os contrastes entre as narrativas dos sujeitos e aquela considerada a "grande narrativa" sobre a reforma psiquiátrica e a saúde mental. $\mathrm{O}$ uso de medicamentos, a forma como os sujeitos tendem a conceber um corpo adoecido e lidar com ele em recuperação, bem como a visão sobre os serviços compõe outro grupo de discussões. Aqui os planos etnográficos que compõe a discussão são: usuários de crack, pessoas em terapias complementares/alternativas, o balcão de uma drogaria, regulamentação de medicamentos, os grupos de ginástica e serviços de atenção básica. Os aspectos éticos das pesquisas são sempre apontados no desenvolvimento dos textos, mas esta questão e o processo de tramitação dos trabalhos antropológicos nos comitês de éticas de pesquisa também é enredo de uma das etnografias, dando margem a pensar sobre os outros artigos que discutem esta condição do trabalho.

O universo das relações entre pesquisadores, interlocutores e serviços, compõe de forma magistral compreensões sobre o adoecimento. Assim, demonstrando que o processo etnográfico se estende até a escrita, o livro trata com cuidado a escolha dos termos para se referirem àquelas pessoas que estão envolvidas com os serviços de saúde, mas não são os profissionais. Há sempre uma discussão que remete esta escolha à garantida da importância do lugar desses sujeitos, seus agenciamentos e também sofrimentos na relação com os serviços de saúde. A necessidade da polissemia de termos como "usuários", “moradores", "experientes”, "grupo", "serviço", “saúde”, "natural” e "mais natural” se baseia na demanda de oferecer significados mais ampliados sobre as condições daqueles que são muito mais do que "pacientes" e trazer as questões dos envolvidos nesses sistemas. Cabe enfatizar que a proposta não é desqualificar os saberes científicos hegemônicos nesse campo, mas "tentar se afetar por formas minoritárias de expressão que tenham potenciais de desestabilizar de algum modo conhecimentos já legitimados." (p.59)

Há um conjunto de artigos que trazem singularidades sobre a forma como os modelos terapêuticos são gerenciados e negociados de acordo com os profissionais e usuários envolvidos. Nestes textos as etnografias oferecem olhares sobre as formas de compreender os serviços de saúde a partir de como eles são constituídos e como eles constituem sujeitos - sejam estes profissionais que estão nos serviços, sejam usuários ou outros envolvidos. Nas etnografias de um centro humanitário ou um CAPS, onde os pesquisadores adentram o universo dos profissionais assumindo/negociando funções, estas questões ganham densidade etnográfica. Nos textos sobre o grupo de ginástica ou sobre terapias alternativas, onde os pesquisadores participam do universo dos usuários, percebe-se que o que caracterizava a assiduidade ao tratamento são, principalmente, os laços de afeto e amizade constituídos pelos usuários. 
O livro aborda em que medida a concepção dos profissionais da atenção à saúde modela a forma como os serviços são executados e também a forma como as pessoas agenciam suas relações com o sistema de saúde. Dando margem a pensar sobre os atravessamentos e atenuantes existentes nas formas de produzir, discutir e praticar o cuidado. As políticas públicas se propõem a um modelo de atenção, mas são nas relações profissionais e com os usuários que os limites e potenciais dessas políticas podem ser descritos e analisados. É na prática, observando os aspectos mais diretos do trabalho, que se pode entender outras questões sobre a produção de políticas públicas para o campo da saúde e a forma como elas são executadas.

É central no livro a ideia de autonomia dos sujeitos elaborada pelos serviços de saúde e como estes tendem, muitas vezes, a desqualificar a agência e as prerrogativas dos usuários. Alguns modelos terapêuticos naturalizam modos de ser adoecido e não compreendem as formas de autonomia expressas pelos usuários em seus processos de tratamento, colocando-os como passivos de um modelo terapêutico. Desprestigiando a autonomia que deveria ser o ponto central na composição de propostas terapêuticas que considerem a realidade e as potencialidades desses sujeitos, suas trajetórias de recuperação e tratamentos. Aqui, a etnografia nos aponta para a forma como os modelos terapêuticos são colocados em prática e como a falta de diálogo com o público envolvido gera abismos nos resultados alcançados por essas políticas públicas.

Deste modo um ponto importante e que alinhava todos os capítulos do livro diz respeito aos atravessamentos que os sujeitos sofrem e oferecem nos/aos serviços de saúde e políticas públicas; etnografando as relações entre serviços e profissionais, entre profissionais e usuários e entre usuários e serviços. É na observação dessas relações que percebemos que os sujeitos não estão passivos a seus processos, que eles estão atentos ao sistema de saúde que se propõe a organizar aspectos do adoecimento. Pois os saberes são constituídos nas experiências com o próprio serviço. Neste sentido, são as etnografias que nos proporcionam condições de entender como o diálogo e a compreensão dos agenciamentos sociais são importantes no processo saúde-doença, bem como na proposição de sistemas de tratamentos e curas. São as diferentes formações e experiências tanto dos profissionais quanto dos usuários que permite uma flexibilização no cotidiano dos serviços e como ele é realmente executado.

O livro leva o leitor a perceber que os usos feitos dos serviços de saúde mostram muito sobre a forma como as pessoas lidam com seus adoecimentos, com seus corpos e também com o aparato biomédico do cuidado; a exemplo dos capítulos que abordam medicalização e tratamentos relacionados ao movimento corporal. O uso que se faz dos equipamentos de saúde, a forma como interagem com os profissionais e com questões cotidianas de seus tratamentos (como consultas e medicamentos) apontam para um campo muito rico e que só é percebido graças ao trabalho etnográfico. Entender como os usuários lidam e agenciam seus tratamentos e seus adoecimentos, a partir dos equipamentos dispostos, produz um conhecimento que vai além do saber biomédico e que aponta caminhos para uma melhor compreensão das questões desses usuários e das formas de fazer as políticas públicas e os serviços de saúde. Pois é em meio ao reconhecimento da autonomia dos sujeitos que se podem elaborar novos modos de pensar esses serviços, permitindo melhor acolhimento e cuidado. 
O livro, ademais, nos mostra como a ideia de movimento é importante para a pesquisa antropológica, seja o caminhar pela cidade, seja o se deslocar pelos serviços, o movimentar-se apresenta concepções dos sujeitos sobre os serviços de saúde e, as narrativas sobre esta relação ganham cenários próprios. No texto sobre sujeitos no contexto da Reforma Psiquiátrica é caminhando pela cidade com os interlocutores que a antropóloga pôde perceber quais os efeitos dessa política no cotidiano, nas ruas e na forma de viver a cidade. Noção esta jamais percebida quando o foco está somente na condição do doente e não da pessoa que mantém outros vínculos além dos hospitais. Contexto este que só pode ser acessado quando se atravessa as barreiras invisíveis das hierarquias e dos distanciamentos naturalizados.

Também importante neste livro é o olhar sobre a relação entre antropólogos/as com os profissionais de saúde e com os usuários dos serviços. Nas etnografias percebemos como o lugar deste pesquisador, muitas vezes, é constituído de um imaginário que provoca novos rumos para a pesquisa. Quando o/a antropólogo/a passa a atuar de forma mais direta juntos com os profissionais de saúde, ou quando estes mesmos pesquisadores passam a fazer uso do serviço como usuários/as os interesses da pesquisa podem tomar outras direções, principalmente, pelo fato dessas relações provocarem aberturas ou fechamentos à algumas questões Esta é uma condição referência da antropologia, e é ela que permite uma observação mais direta, modelando um campo de negociações entre pesquisadores e interlocutores, bem como com aquelas pessoas que estão imersa no universo de investigação. E do ponto de vista das etnografias em serviços de saúde este é um momento de discussão teórico-metodológico, pois nesse processo é possível conhecer as concepções dos usuários e profissionais sobre o sistema de saúde e suas relações.

Estas etnografias despertam, portanto, novos olhares sobre os aspectos mais comuns dos serviços de saúde. Elas ultrapassam as barreiras das paredes claras e do ambiente asséptico que indicam limpeza dos equipamentos dos serviços de saúde. Apontam para a vida e as relações que ali existem e que envolvem a estrutura, os profissionais e os usuários. Principalmente, são as etnografias dos serviços de saúde que despertam questões sobre como estes serviços afetam as vidas das pessoas, como são usados por elas, como são negociados e como se modificam ou são adaptados a partir das relações existentes.

Questôes estas pouco percebidas quando o foco está somente na ideia de adoecimento e não nos sujeitos envolvidos no processo saúde-doença. Aqui está a grande contribuição que a antropologia e as etnografias em serviços de saúde podem oferecer; elas ajudam a ampliar o olhar para a multiplicidade existente nesses contextos. Por fim, este livro pode oferecer grande contribuição para ampliar as ferramentas de investigação de estudantes das Ciências Sociais e, principalmente, das Ciências da Saúde, pois apresenta outros olhares e outras formas de discutir sobre o universo dos serviços de saúde, promovendo desconstruções necessárias no processo de formação de profissionais que serão considerados saberes hegemônicos.

\section{Tatiane Vieira Barros é doutoranda em Antropologia Social pelo Programa de Pós-graduação da UFSC.}

RECEBIDO: $06 / 03 / 2017$

APROVADO: $25 / 10 / 2017$ 